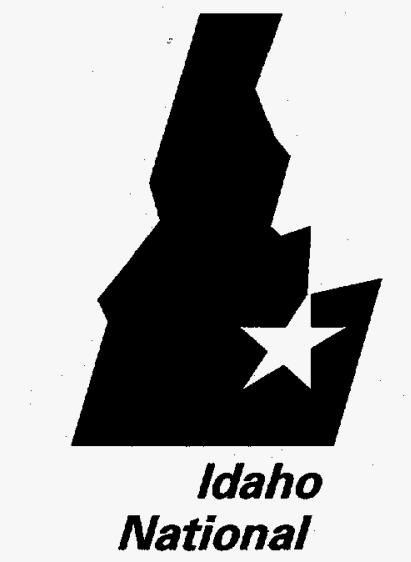

Engineering Laboratory
INEL-94/0215

May 1996

Polyphosphazene Membranes for Metal Ion Separations

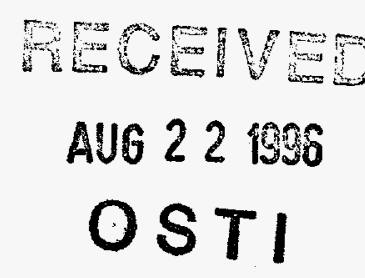

M. L. Stone

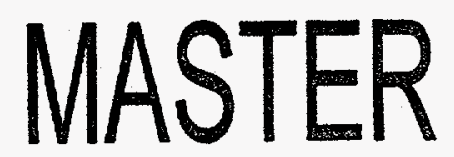

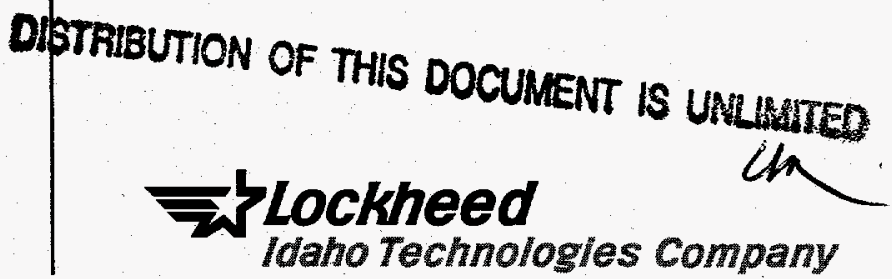





\section{Polyphosphazene Membranes for Metal Ion Separations}

M. L. Stone

Published May 1996

Idaho National Engineering Laboratory

Lockheed Idaho Technologies Company

Idaho Falls, Idaho 83415

Prepared for the

Interior Department's Bureau of Mines

under Contract No. J0134035

through DOE Idaho Operations Office

Contract No. DE-AC07-94ID13223 



\section{DISCLAIMER}

Portions of this document may be illegible in electronic image products. Images are produced from the best available original document. 



\section{ABSTRACT}

Polyphosphazene linear polymer membranes have been evaluated in metal ion separation processes. Poly(bisphenoxy)phosphazene (PPOP) is very hydrophobic and showed very low metal ion fluxes. When this material was modified by adding carboxyl functional groups it became hydrophilic and a 2 to 3 order of magnitude increase in metal ion flux was achieved. However, no selectivity was observed for cobalt, copper, manganese, and nickel ions. The only selectivity observed was in experiments involving chromium ions, which under the experimental conditions formed dimers that were too large to permeate the membrane. Chromium was separated from cobalt and manganese because of the dimer formation.

In reverse osmosis experiments, PPOP membranes removed $50 \%$ of the metal ions in a single pass. The procedure was to force water through a membrane while retaining the metal ions (cobalt, copper, manganese, and nickel) in the rejectate. This process could be used to concentrate valuable metal ions or remove heavy metals from processing waste streams.

Polyphosphazene polymers have proven to be very chemical and temperature resistant. Reverse osmosis experiments exposed the membranes to $97^{\circ} \mathrm{C}$ and 200 psi pressure. Simple diffusion tests with metal ions exposed the membranes to $\mathrm{pH} 2$ at elevated temperatures for weeks at a time with little evidence of degradation.

The direct connection between chemical structure and performance has been shown in polyphosphazene chemistry; PPOP was metal ion impermeable, whereas carboxylated PPOP was permeable to all the metals tested. 


\section{ACKNOWLEDGMENTS}

The author acknowledges the contributions of C. A. Allen and R. R. McCaffrey, prior principal investigators, who initiated and directed the membrane research program. Thanks is also expressed to A. E. Grey, technical leader, R. E. McAtee, scientific specialist, D. G. Cummings, scientist, and Kim Arehart, technician, for their technical assistance in experimental design and execution. The author gratefully acknowledges E. S. Peterson, senior scientist, for his significant contributions to the overall program. In addition, the author thanks G. L. Vivian, Bureau of Mines technical program officer, V. W. Storhok, program manager, and J. D. Weyand, program manager, for their suggestions.

\section{DISCLAIMER}

This report was prepared as an account of work sponsored by an agency of the United States Government. Neither the United States Government nor any agency thereof, nor any of their employees, makes any warranty, express or implied, or assumes any legal liability or responsibility for the accuracy, completeness, or usefulness of any information, apparatus, product, or process disclosed, or represents that its use would not infringe privately owned rights. Reference herein to any specific commercial product, process, or service by trade name, trademark, manufacturer, or otherwise does not necessarily constitute or imply its endorsement, recommendation, or favoring by the United States Government or any agency thereof. The views and opinions of authors expressed herein do not necessarily state or reflect those of the United States Government or any agency thereof. 


\section{CONTENTS}

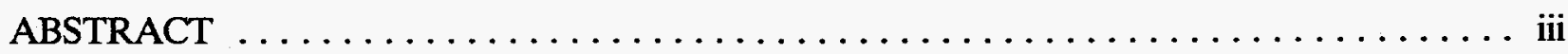

ACKNOWLEDGMENTS $\ldots \ldots \ldots \ldots \ldots \ldots \ldots \ldots \ldots \ldots \ldots \ldots \ldots \ldots \ldots \ldots$

INTRODUCTION $\ldots \ldots \ldots \ldots \ldots \ldots \ldots \ldots \ldots \ldots \ldots \ldots \ldots \ldots \ldots \ldots \ldots \ldots \ldots \ldots \ldots$

POLYMER SELECTION AND PREPARATION $\ldots \ldots \ldots \ldots \ldots \ldots \ldots \ldots \ldots \ldots, 1$

Background $\ldots \ldots \ldots \ldots \ldots \ldots \ldots \ldots \ldots \ldots \ldots \ldots \ldots \ldots \ldots \ldots \ldots \ldots \ldots \ldots \ldots$

LINEAR POLYMER SYNTHESIS $\ldots \ldots \ldots \ldots \ldots \ldots \ldots \ldots \ldots \ldots \ldots \ldots \ldots \ldots \ldots \ldots$

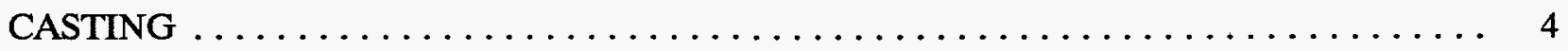

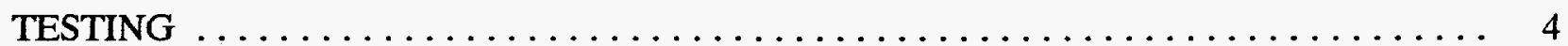

DATA ANALYSIS FOR SEPARATIONS INVOLVING CHROMIUM, COBALT,

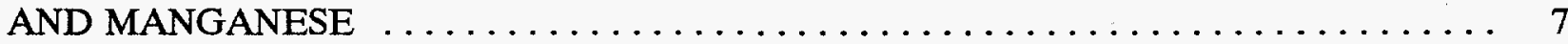

Tests Involving PPOP Membranes $\ldots \ldots \ldots \ldots \ldots \ldots \ldots \ldots \ldots \ldots \ldots \ldots \ldots \ldots \ldots$

Tests Involving PTFEP Membranes $\ldots \ldots \ldots \ldots \ldots \ldots \ldots \ldots \ldots \ldots ., 9$

SUMMARY OF THE CHROMIUM, COBALT, AND MANGANESE SEPARATIONS $\ldots \quad 9$

DATA ANALYSIS FOR SEPARATIONS INVOLVING COBALT, COPPER,

MANGANESE, AND NICKEL $\ldots \ldots \ldots \ldots \ldots \ldots \ldots \ldots \ldots \ldots \ldots \ldots \ldots \ldots \ldots \ldots \ldots$

Tests Involving Reverse Osmosis $\ldots \ldots \ldots \ldots \ldots \ldots \ldots \ldots \ldots \ldots \ldots \ldots \ldots$

SUMMARY AND CONCLUSIONS $\ldots \ldots \ldots \ldots \ldots \ldots \ldots \ldots \ldots \ldots \ldots \ldots \ldots \ldots \ldots \ldots$

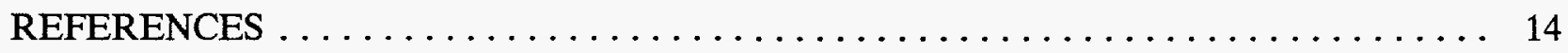

\section{FIGURES}

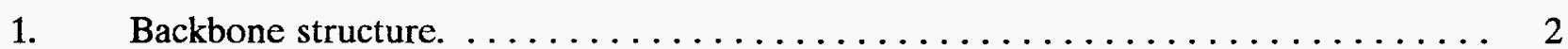

2. Ratio of diffusion coefficients (a) Cobalt and Manganese, (b) Manganese and Chromium, (c) Cobalt and Chromium.

3. Two-chamber apparatus for separation testing. $\ldots \ldots \ldots \ldots \ldots \ldots \ldots \ldots \ldots$ 
4. Comparison of the diffusion coefficients through PTFEP and PPOP (a) $\mathrm{Co}^{2+}$, (b) $\mathrm{Mn}^{2+}$, (c) $\mathrm{Cr}^{3+}$.

5. Concentrations of metal ions in the permeate as a function of time and temperature for $8 \%-\mathrm{COOH}-\mathrm{PPOP}$.

\section{TABLES}

1. Ionic radii and diffusion activation energies for $\mathrm{Cr}^{3+}, \mathrm{Co}^{2+}$, and $\mathrm{Mn}^{2+} \ldots \ldots \ldots$

2. Metal ion concentration by reverse osmosis $\ldots \ldots \ldots \ldots \ldots \ldots \ldots \ldots \ldots$ 


\section{POLYPHOSPHAZENE MEMBRANES FOR METAL ION SEPARATIONS}

\section{INTRODUCTION}

The Idaho National Engineering Laboratory (INEL), under sponsorship by the Bureau of Mines, evaluated the use of polyphosphazene-based polymer membranes for chemical separations. Synthetic membranes based on phosphazene inorganic polymers offer the promise of new industrial chemical separation technologies that are more energy efficient and economical than traditional phase change separation processes and extraction techniques. The research focused on the separation of metal ions from aqueous solutions. The polyphosphazene membranes were also tested for gaseous separations, results of which are presented in a separate Report of Investigation.

Historically, membranes used for chemical separation have been prepared from organic polymers. In general, these membranes are stable only at temperatures less than $100^{\circ} \mathrm{C}$, within narrow $\mathrm{pH}$ ranges, and in a very limited number of organic media. As a result, many organicbased membranes are unsuitable for industrial applications, which often involve harsh environments. In recent years, membrane research has focused on ceramic and metal membranes for use in the adverse environments of separation applications. These membranes are suitable for gas and liquid sieve separation applications, where molecules may be separated based on their molecular size. These membranes are not effective where additional selectivity is needed. A membrane that separates on the basis of solubility and that can perform separations in adverse environments is needed, and this need motivated the investigation of polyphosphazene membranes.

\section{POLYMER SELECTION AND PREPARATION}

\section{Background}

Phosphazene polymers consist of alternating phosphorus and nitrogen atoms attached by alternating single and double bonds. In addition, each phosphorus atom forms two bonds to side groups. The virtually limitless number of possible side groups gives this class of materials a wide spectrum of chemical possibilities. Because the backbone does not contain carbon, it is referred to as an inorganic polymer, even though numerous organic side groups are attached to the polymer backbone. ${ }^{1}$

These polymers can be easily modified with a variety of side groups by nucleophilic substitution and exchange reactions. In addition to varying the side groups, the structure of the backbone itself may be changed to any one of the following three types: linear, cyclolinear, and cyclomatrix. These structures are illustrated in Figure 1. The R groups in figure 1 are used to designate side and/or crosslinking groups (i.e., alcohol, phenol, amino, alkyl, and aromatic groups).

Linear organosubstituted polyphosphazene is synthesized by ring-cleavage polymerization of a cyclic trimer (usually hexachlorotriphosphazene) at $250^{\circ} \mathrm{C}$ under vacuum and subsequent 


\section{Linear Backbone}

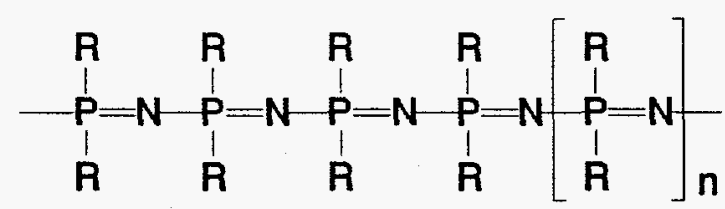

\section{Cyclolinear Backbone}<smiles>[R]P1([R])=NP([R])([2H])=NP(P)(P2([R])=NP([R])([R])=NP([R])(P)=N2)=N1</smiles>

\section{Cyclomatrix Backbone}

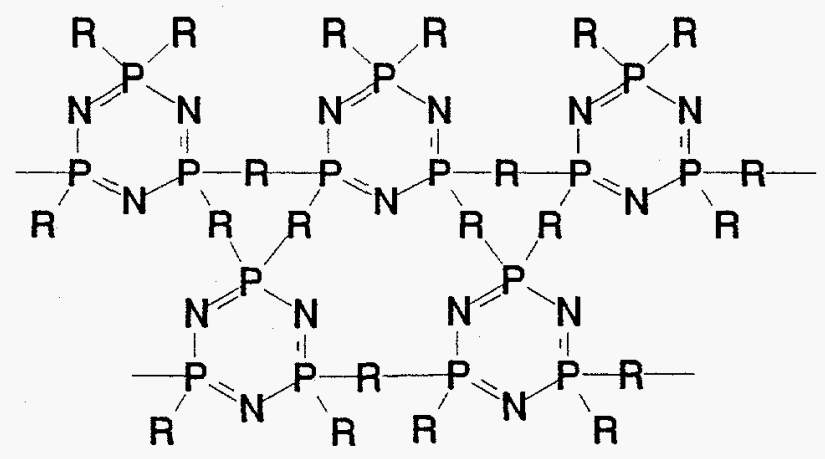

Figure 1. Backbone structure. 
substitution with the desired side group. Cyclolinear and cyclomatrix polymers are prepared by reacting cyclic trimer with difunctional monomers. The type of polymers obtained is dependent on the mole ratios of the reactants and reactive sites on the trimer. Chemical and thermal stability of the polymers increases with the crosslinking of the polymer backbone structure. ${ }^{2}$

Based on previous experience in other related programs, the phosphazene materials selectcd for this project were linear backbone polymers having two side groups, such as phenoxy or substituted phenoxy groups, attached to the phosphorus atoms in the backbone. An example of this type of polymer is poly(bisphenoxy)phosphazene, referred to as PPOP.

PPOP was examined most extensively because it is soluble in tetrahydrofuran (THF) and 1,4-dioxane, which in turn allowed the PPOP to be readily "cast" from solution into the dense film and asymmetric membranes.

\section{LINEAR POLYMER SYNTHESIS}

The synthesis of all linear polymers is similar, and one representative example will be discussed in detail. PPOP was synthesized using the published method of Singler. ${ }^{3}$ The overall reaction for the synthesis of PPOP is:

$\left[\mathrm{N}=\mathrm{P}(\mathrm{Cl})_{2}\right]_{\mathrm{n}}+2 \mathrm{n} \mathrm{NaOC} \mathrm{H}_{5} \cdots\left[\mathrm{N}=\mathrm{P}\left(\mathrm{OC}_{6} \mathrm{H}_{5}\right)_{2}\right]_{\mathrm{n}}+2 \mathrm{n} \mathrm{NaCl}$.

The synthesis procedure can be summarized as:

1. Hexachlorocyclotriphosphazene was polymerized under vacuum at $250^{\circ} \mathrm{C}$ for $48 \mathrm{~h}$ to produce polydichlorophosphazene.

2. The polydichlorophosphazene was dissolved in benzene and purified by precipitation into heptane.

3. The pure polydichlorophosphazene was dissolved in dry toluene and added to a benzene[bis(2-ethoxy ethyl)ether] solution containing 20 mole percent excess sodium phenoxide. (Mole percentages are based on the number of moles of chlorine in polydichlorophosphazene.)

4. This solution was refluxed at $110^{\circ} \mathrm{C}$ in the absence of light for $42 \mathrm{~h}$, during which time the $\mathrm{Cl}$ atoms were replaced by phenoxy groups.

5. After cooling, the product, PPOP, was precipitated into a large excess of methanol.

6. The solids (including the product) were separated by filtration and were washed with water and methanol to remove occluded sodium chloride.

7. The polymer was purified by dissolving in THF and precipitation into a large excess of water. 
8. Following air drying, the polymer was further purified with petroleum ether in a soxhlet extractor for $48 \mathrm{~h}$.

Yields of 50 to $60 \%$ were achieved using this method. The resulting polymer was a white, fibrous, flexible, film-forming material that dissolved in THF. The polymer was characterized with infrared analysis and differential scanning calorimetry (DSC); the results matched literature values. $^{4,5}$ Molecular weights were determined using gel permeation chromatography and polystyrene standards for comparison. These characterizations yield important information regarding the polymer's purity, chemical structure, in addition to molecular weight; all have a bearing on the polymer's ability to form a thin film and to function as a membrane. Other polymers such as poly(bistrifluoroethoxy)phosphazene (PTFEP) were synthesized in similar procedures. ${ }^{6}$

\section{CASTING}

Membranes were solution cast onto glass plates. Casting was performed by simply pipetting approximately $8 \mathrm{~mL}$ of a THF solution containing 1 to $5 \%$ polymer onto a glass plate and allowing the solvent to evaporate. Once dry, the edges of the membrane were loosened by a knife and the plate was lowered into a water bath very slowly so that the water came in contact with the edge but did not cover the film. The water worked its way under the film and the membrane floated off. It was then easily transferred to the holder and mounted in the cell. In some cases the membranes were cast using knife (draw-down bar) casting techniques. To vary membrane thickness, either the polymer solution concentration or knife height was changed.

Film thicknesses were determined from scanning electron microscope (SEM) photographs of the membrane edge taken at the conclusion of a series of experiments. There is uncertainty in the thickness measurement because of stretching, compression, and rolling of the membrane material when removed from the support and from the angle of view.

\section{TESTING}

All diffusion tests were performed using the liquid test cell. In all cases involving a mixture of the three ions ( $\mathrm{Mn}, \mathrm{Co}$, and $\mathrm{Cr}$ ), the feed solution contained $0.01 \mathrm{M} \mathrm{Cr}\left(\mathrm{NO}_{3}\right)_{3} \cdot 9 \mathrm{H}_{2} \mathrm{O}$, $0.01 \mathrm{M} \mathrm{Mn}\left(\mathrm{NO}_{3}\right)_{2}$ and $0.01 \mathrm{M} \mathrm{Co}\left(\mathrm{NO}_{3}\right)_{2} 6 \mathrm{H}_{2} \mathrm{O}$. Demineralized water was used as the carrier fluid to sweep the permeate from the back of the membranes to maintain a constant concentration gradient.

Before each test, a leak test was performed to verify membrane integrity. This test consisted of pressurizing the feed side to 50 psid relative to the permeate side. If fluid appeared at the back of the test cell, the membrane was rejected. If the membrane was accepted, a 10 psid pressure differential was established across the membrane and the system temperature raised to the experimental condition. The system was allowed to operate for $1-1 / 2 \mathrm{~h}$ to establish steady state before the first sample was taken. During a 20 -min sampling period, the feed and permeate flow rates were measured volumetrically, and the temperature and pressures were recorded. Typical flow rates were $1.0 \mathrm{~mL} / \mathrm{min}$ for the permeate and $25 \mathrm{~mL} / \mathrm{min}$ for the feed. $\mathrm{Mn}, \mathrm{Co}$, and $\mathrm{Cr}$ concentrations in the feed, rejectate, and permeate were measured by atomic absorption 
spectrometry. The samples were also analyzed for $\mathrm{Fe}$ and $\mathrm{Ni}$ to verify that these species remained below the threshold concentration for interference.

Using the permeate and feed concentrations, membrane thickness, sample time, sample volume, and surface area of the porous support, diffusion coefficient ratios were calculated. Diffusion coefficient ratios are of particular significance when evaluating the separation properties of a membrane material. The general diffusion equation, for diffusion through a thin film under the boundary conditions of the experiment, used to calculate the diffusion coefficient is:

$$
D_{i}=F_{i} \ell\left(C_{i 1}-C_{i 2}\right)
$$

where

$$
\begin{array}{ll}
\mathrm{D}_{\mathrm{i}} & =\quad \text { the diffusion coefficient for species } \mathrm{i} \\
\mathrm{F}_{\mathrm{i}} & =\quad \text { the flux of species } \mathrm{i} \text { through the membrane } \\
\ell & =\quad \text { the membrane thickness } \\
\mathrm{C}_{\mathrm{i} 1} & =
\end{array}
$$

The diffusion coefficient ratio for two species diffusing through the same membrane is:

$$
D_{i} / D_{j}=F_{i}\left(C_{j 1}-C_{j 2}\right) / F_{j}\left(C_{i 1}-C_{i 2}\right)
$$

This expression has the advantage that the membrane thickness, which in our experiments is subject to the most experimental error, is not part of the calculation.

The diffusion coefficient ratios for $\mathrm{Co}, \mathrm{Cr}$, and $\mathrm{Mn}$ as functions of temperature are shown in Figure 2. Diffusion coefficients for each cation species were calculated for each experimental temperature using membrane thicknesses measured by scanning electron microscopy. Using the discrete solid state diffusion model discussed by Starzak ${ }^{7}$ and modified by McCaffrey et al., ${ }^{8}$ activation energies for diffusion can be described by:

$$
D_{i}=D_{0} \exp \left(-\Delta E_{m i} / k T\right)
$$

where

$$
\begin{aligned}
& \mathrm{D}_{\mathrm{i}}=\text { the calculated diffusion coefficient from Equation (1) } \\
& \mathrm{D}_{0}=\text { is related to the ionic jump rate from the feed into the membrane }
\end{aligned}
$$




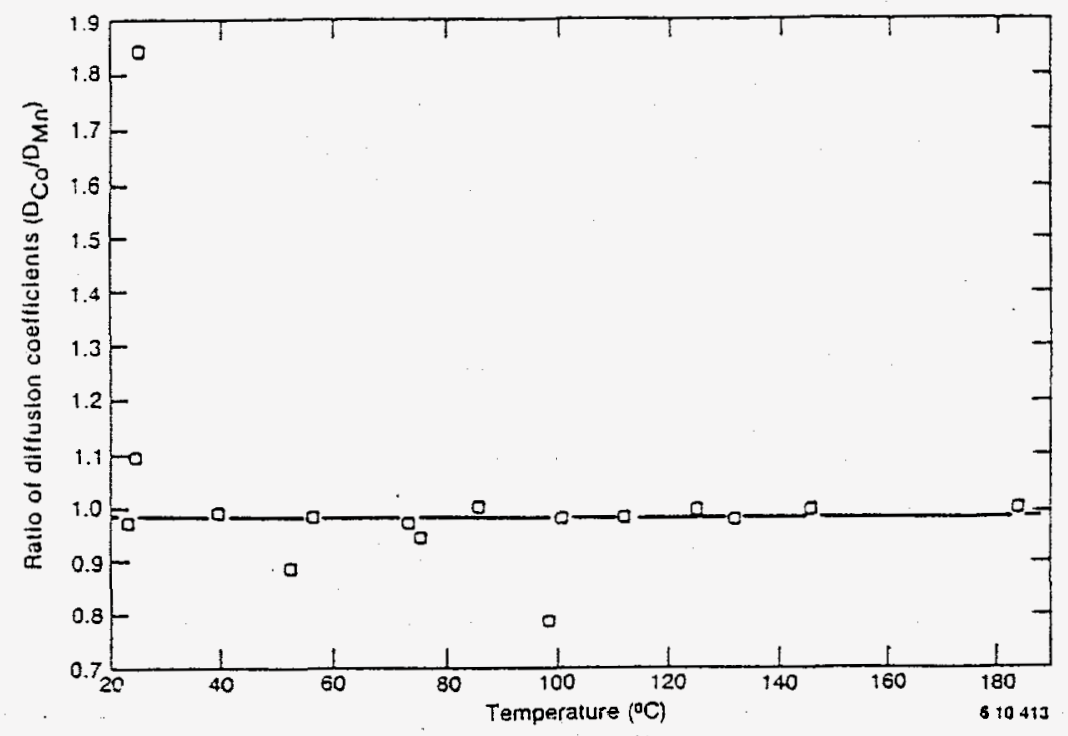

(a)

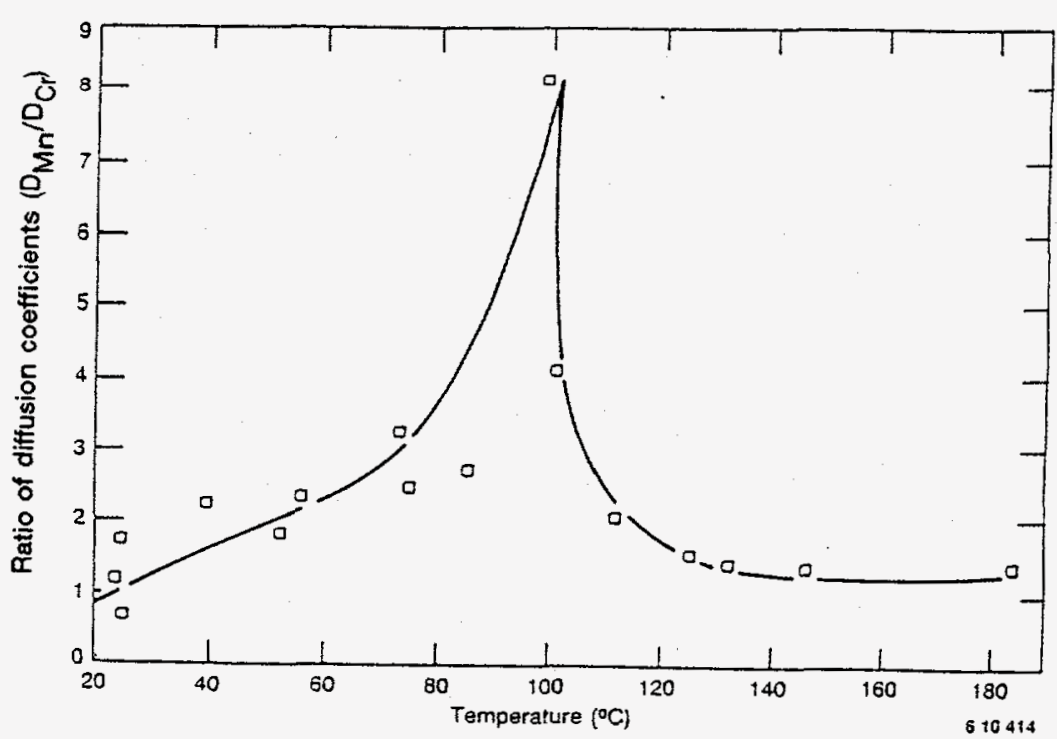

(b)

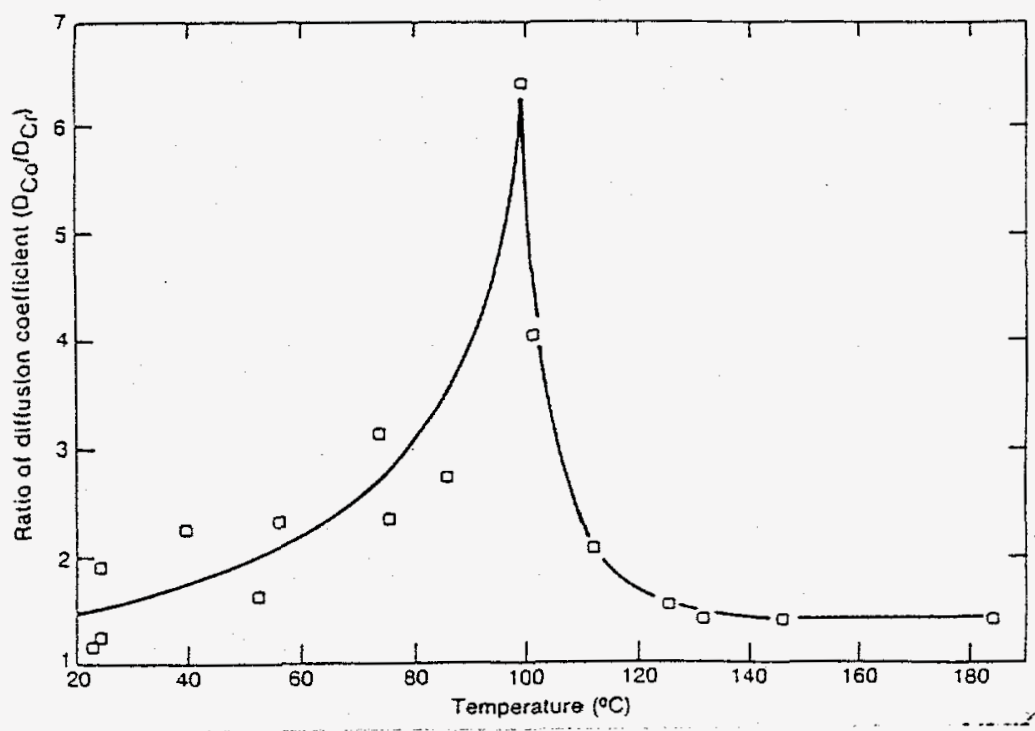

(c)

Figure 2. Ratio of diffusion coefficients (a) Cobalt and Manganese, (b) Manganese and Chromium, (c) Cobalt and Chromium. 
$\mathrm{k} \quad=\quad$ Boltzmann's constant $\mathrm{T}$ is the absolute temperature

$\Delta \mathrm{E}_{\mathrm{mi}}=\quad$ the activation energy. $\Delta \mathrm{E}_{\mathrm{mi}}$ is calculated from a plot of $\log \mathrm{D}_{\mathrm{i}}$ vs. $1 / \mathrm{T}$.

The simple diffusion experimental apparatus used for the four ion mixture ( $\mathrm{Co}, \mathrm{Cu}, \mathrm{Mn}$, and $\mathrm{Ni}$ ) is shown in Figure 3. It consists of a two-chambered plexiglas box separated by a partition containing a membrane. The metal ions are loaded into one of the chambers and pure water is placed in the other. Then, over time, samples are collected from each chamber and analyzed for metal ions with an inductively coupled plasma (ICP) instrument. Experimental parameters that were varied are membrane type, temperature, and $\mathrm{pH}$.

\section{DATA ANALYSIS FOR SEPARATIONS INVOLVING CHROMIUM, COBALT, AND MANGANESE}

\section{Tests Involving PPOP Membranes}

The data in Figures 2(b) and (c) indicate that chromium is separated from cobalt and manganese in aqueous solution by PPOP membranes and that a maximum in the separation occurs near $100^{\circ} \mathrm{C}$. It was also observed that during the higher temperature runs, the rejectate turned a dark green, compared with the dark purple feed, and the $\mathrm{pH}$ decreased. These results indicate that a hydrolysis reaction is taking place when the solution heats.

It is known that chromium hexahydrate in aqueous solution forms a hydroxyl species that forms polymers in the presence of a base or at elevated temperatures. ${ }^{9}$ Chromium hexahydrate is violet; but when the hydroxyl species is formed, the color turns dark green.

It appears that the polymerized $\mathrm{Cr}^{3+}$ species forms in the feed solution and that the larger polymerized hydrated form of $\mathrm{Cr}^{3+}$ is less likely to permeate the PPOP membrane than the unpolymerized $\mathrm{Mn}^{2+}$ and $\mathrm{Co}^{2+}$ ions. This conclusion is further supported by the calculated activation energies shown in Table 1 . Activation energies are in the order predicted by ionic radii. $^{10}$

Table 1. Ionic radii and diffusion activation energies for $\mathrm{Cr}^{3+}, \mathrm{Co}^{2+}$, and $\mathrm{Mn}^{2+}$.

\begin{tabular}{ccc}
\hline Ionic species & Ionic radii, $\mathrm{nm}$ & Activation energy, $\mathrm{eV}$ \\
\hline $\mathrm{Cr}^{3+}$ & 0.064 & 0.14 \\
$\mathrm{Co}^{2+}$ & 0.072 & 0.16 \\
$\mathrm{Mn}^{2+}$ & 0.080 & 0.17 \\
\hline
\end{tabular}




\section{Two-Chamber Diffusion Apparatus}

Sampling Port Heaters/Temperature Controllers Sampling Port

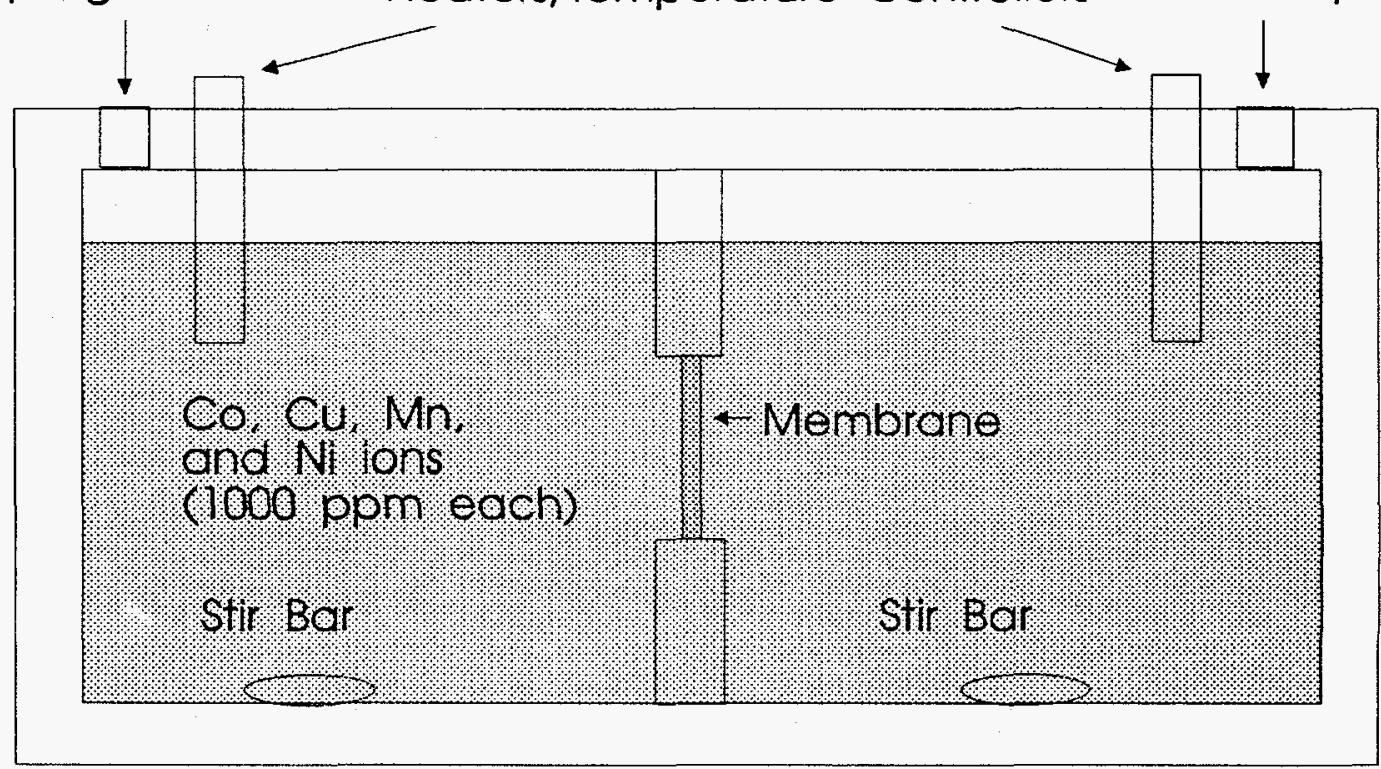

Feed Solution Chomber Permeate Solution Chamber

Figure 3. Two-chamber apparatus for separation testing. 
Since the activation energies align with the ionic radii, it is probable that the diffusing species are the ions. It is not clear at this time if the ions are hydrated or unhydrated. The lower diffusion coefficient for chromium ions are related to the preexponential term and are most likely due to a lower jump frequency from the feed solution into the membrane surface. This is a natural consequence of the equilibrium between the polymerized chromium ions and the unpolymerized chromium ions, which in effect reduces the concentration of chromium that can enter the membrane.

The diffusion coefficient of $\mathrm{Cr}^{3+}$ through PPOP is lower than the diffusion coefficients of $\mathrm{Mn}^{2+}$ and $\mathrm{Co}^{2+}$ through the same membrane. A maximum in the separation appears near $100^{\circ} \mathrm{C}$. This phenomenon is related to the hydrolysis behavior of chromium and could be the basis for new hydrothermal separation processes.

\section{Tests Involving PTFEP Membranes}

The same casting and testing procedures were used with this second membrane to compare its performance to that observed previously with PPOP. PTFEP was expected to be much more hydrophobic than PPOP due to the presence of the fluorine groups on the ligands due to the highly electronegative surface of the PTFEP. As a result, one would expect the jump distance from the feed solution into the membrane to be greater for PTFEP. Figure 4 confirms this phenomenon. This figure compares the diffusion coefficients of PPOP and PTFEP for each of the metal ions in this study. The results show that: (a) the diffusion coefficients for $\mathrm{Cr}^{3+}$ are about a factor of 11 less than the diffusion coefficients for $\mathrm{Co}^{2+}$ and $\mathrm{Mn}^{2+}$, and (b) the diffusion of cobalt, manganese, and chromium ions is at least 50 times slower through PTFEP than through PPOP.

\section{SUMMARY OF THE CHROMIUM, COBALT, AND MANGANESE SEPARATIONS}

Overall observations concerning these two phosphazene polymer membranes are (a) phosphazene polymers can be cast into membranes, (b) they are stable at temperatures up to $180^{\circ} \mathrm{C}$ in the presence of alcohols, (c) their chemistry can be altered to change their separation performance, (d) they demonstrated separation factors of a magnitude useful for metal ion separations, and (e) the fluxes through membranes were low.

\section{DATA ANALYSIS FOR SEPARATIONS INVOLVING COBALT, COPPER, MANGANESE, AND NICKEL}

Four different polymeric formulations were tested in this set of experiments. The first two were very hydrophobic. These two membranes were poly(methoxy-ethoxytrifluoroethoxy)phosphazene and poly-bis(meta-methylphenoxy) phosphazene. After $400 \mathrm{~h}$ of testing, neither of these two membranes had allowed over $1 \mathrm{ppm}$ of any of the ions through.

To make a more hydrophilic material, a membrane was prepared by exposing a regular PPOP membrane to sulfur trioxide. The separation experiments were then run immediately, but 


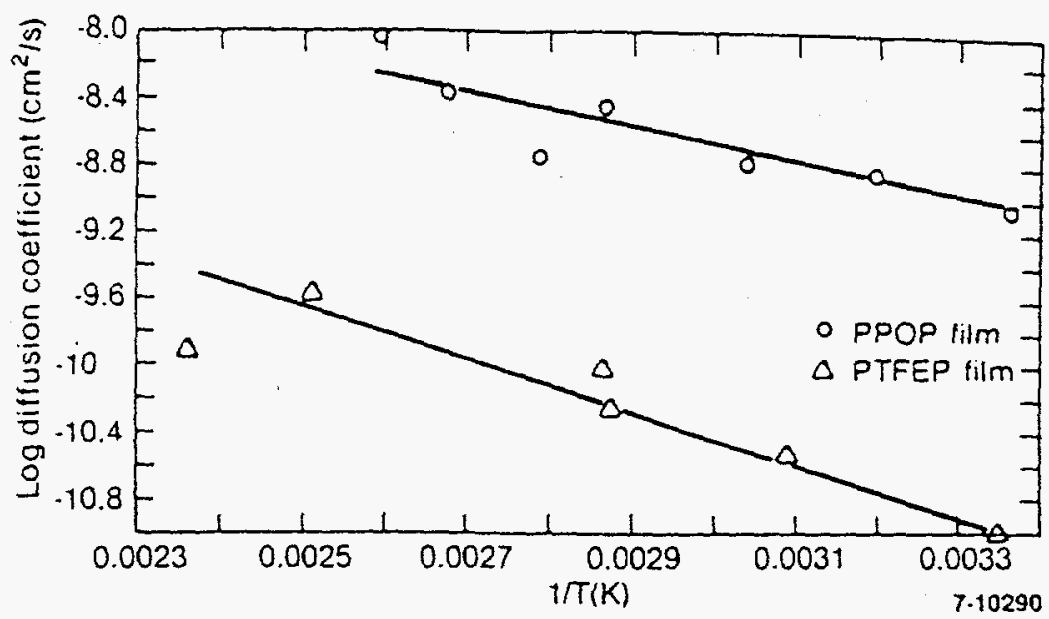

(a)

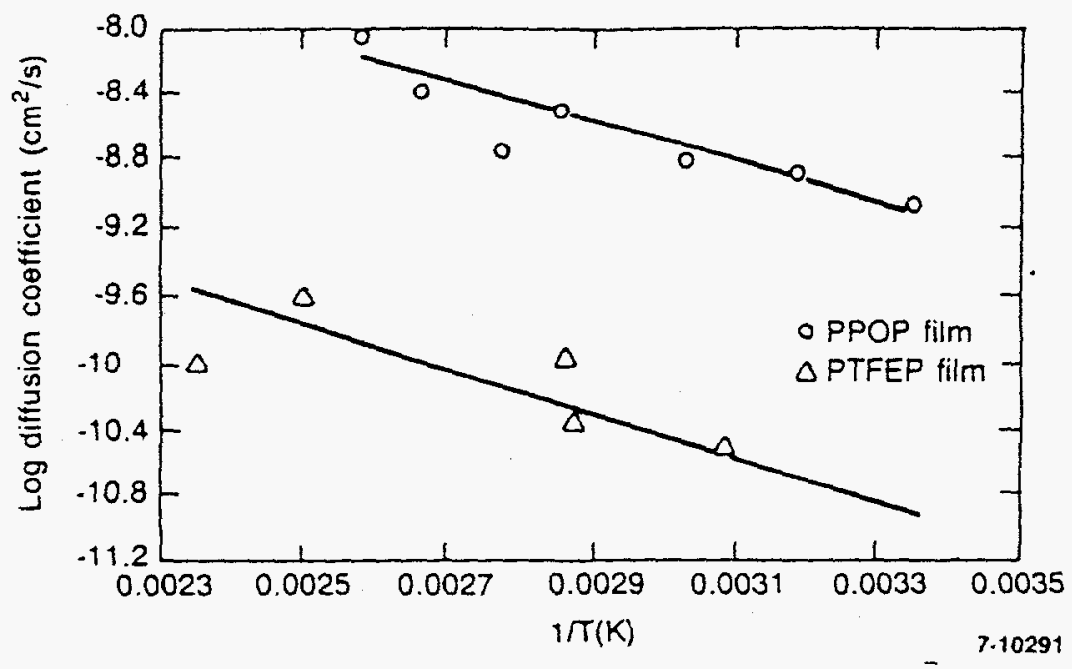

(b)

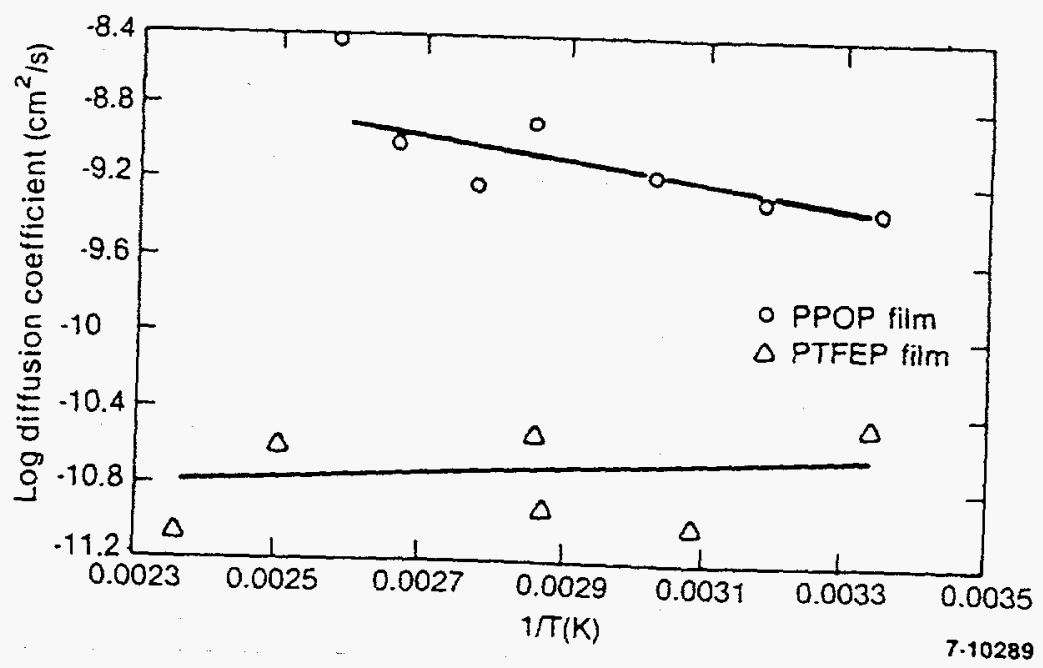

(c)

Figure 4. Comparison of the diffusion coefficients through PTFEP and PPOP (a) $\mathrm{Co}^{2+}$, (b) $\mathrm{Mn}^{2+}$,
(c) $\mathrm{Cr}^{3+}$. 
little improvement was observed. Subsequent analysis showed that a permanent sulfonation had not taken place.

A PPOP polymer in which approximately $8 \%$ of the phenoxy groups had a carboxy group attached was synthesized (labeled $8 \%-\mathrm{COOH}-\mathrm{PPOP}$ ). The test results were dramatic (see Figure 5). In the first $450 \mathrm{~h}$ at room temperature close to $100 \mathrm{ppm}$ of each of the ions had permeated. The temperature was raised to $50^{\circ} \mathrm{C}$, and in the following $150 \mathrm{~h}$ the concentration increased to more than $250 \mathrm{ppm}$ for all of the ions, showing that by varying the polymer indeed could permit permeation by the metal ions. Even though this membrane was not selective, it does illustrate one of the main premises of this program; which is that the chemistry of the polymer can be modified to change its performance. Perhaps another polymer variation could be selected that would show selectivity as well. Another important point is that there are many different metal ion separations needed, and the results here are for only one group of very similar metal ions.

\section{Tests Involving Reverse Osmosis}

Another separation that would be useful in the mining industry and in waste minimization would be the concentration of metal ions from dilute process or waste streams or the clean up of process waters for recycle. With this premise and the knowledge that some of the membranes did not allow metal ions to readily transport through them, a set of reverse osmosis experiments were run. In reverse osmosis, water is forced through the membrane using higher temperatures and pressures in a direction opposite to the direction it would flow based on concentration gradients. An aqueous feed stream containing metal ions was passed across one of the hydrophobic membranes to see if the water could be forced through, leaving the metal ions behind, thus concentrating the ions and purifying the water. It was surmised that if a hydrophilic membrane was used, both the water and ions would permeate.

Table 2 gives results of reverse osmosis with 8\%-COOH-PPOP (hydrophilic) and straight PPOP. The results proved the premise. In the case of the $8 \%-\mathrm{COOH}-\mathrm{PPOP}$, the metal ion concentration is basically the same for both feed and permeate. However, the PPOP membrane restricted the permeation of the metal ions by a factor of two. These scoping experiments show that there is a good possibility that the membranes could be useful in concentrating metal ions in aqueous process and waste streams.

Table 2. Metal ion concentration by reverse osmosis.

\begin{tabular}{|c|c|c|c|c|c|c|c|}
\hline Membrane & $\underset{h}{\text { Run time, }}$ & $\begin{array}{c}\text { Permeate } \\
\text { volume, } \mathrm{mL}\end{array}$ & & $\begin{array}{l}\mathrm{Ni}, \\
\mu \mathrm{g} / \mathrm{g}\end{array}$ & $\begin{array}{l}\mathrm{Co}, \\
\mu \mathrm{g} / \mathrm{g}\end{array}$ & $\begin{array}{l}\mathrm{Mn}, \\
\mu \mathrm{g} / \mathrm{g}\end{array}$ & $\begin{array}{l}\mathrm{Cu}, \\
\mu \mathrm{g} / \mathrm{g}\end{array}$ \\
\hline \multirow[t]{2}{*}{ COOH PPOP } & 5 & 18.5 & Feed & 880 & 911 & 888 & 845 \\
\hline & & & Permeate & 936 & 965 & 946 & 954 \\
\hline \multirow[t]{2}{*}{ PPOP } & 4.5 & 20 & Feed & 947 & 943 & 927 & 901 \\
\hline & & & Permeate & 456 & 453 & 451 & 411 \\
\hline
\end{tabular}




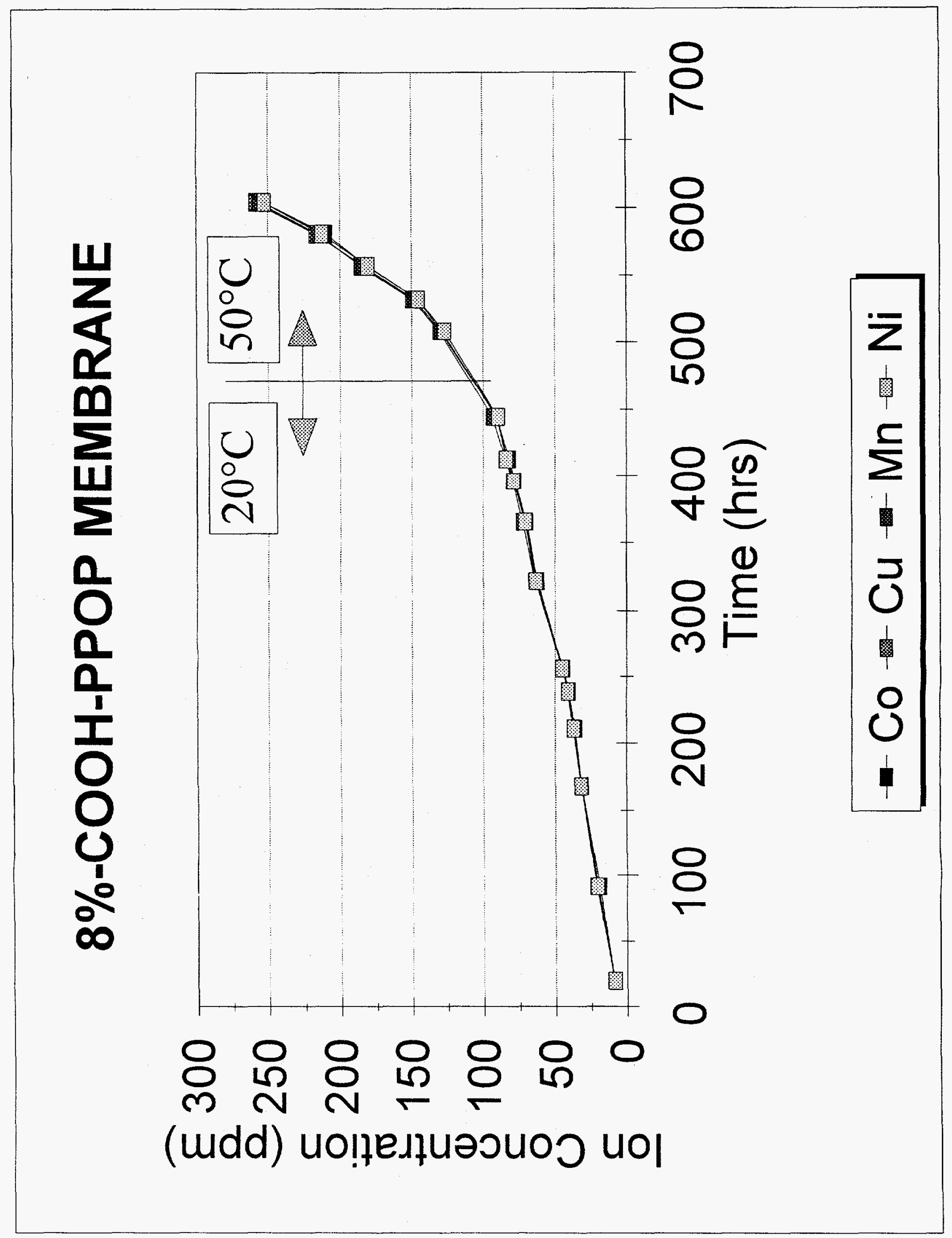

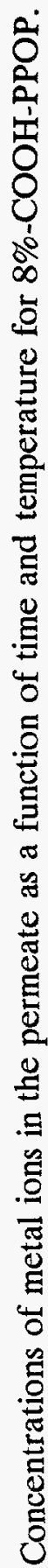
in 옥 


\section{SUMMARY AND CONCLUSIONS}

Polyphosphazene linear polymer membranes have been evaluated for metal ion separation processes. These studies were performed primarily with a group of similar polymers based on poly(bisphenoxy)phosphazene (PPOP). This is a hydrophobic material, as is the methylated PPOP material tested. These materials did not transport metal ions with any usable fluxes. Attempts were made to make more hydrophilic materials. This led to a PPOP with approximately $8 \%$ of the phenoxy groups carboxylated. The modified polymer was much more hydrophilic and transported the four metal ions tested very readily. These results show that the polymer's performance depends on its chemical structure. The carboxylated polymer did not show any selectivity for the ions tested. Selectivity was observed in a metal ion mixture containing chromium under conditions that caused the chromium to dimerize. The chromium dimer was large enough to be hindered from going through the membrane at the same rate as the other metals in the mixture. This result is an important finding because it points to the possibility that both the type of polymer and the environment of the metal ions play an important role in the overall separation of metal ions from solution.

Finally, to take advantage of the fact that some of the membranes did not readily transport metal ions, an experiment was performed to determine if the ions could be concentrated by forcing the water through such a membrane. A reverse osmosis experiment proved in principle that the idea worked. A PPOP membrane retained over half of the metal ions in a solution passed through the membrane at elevated temperatures and pressures. This process could be used to concentrate metal ions or to clean up a waste stream containing metal ions. 


\section{REFERENCES}

1. Allcock, H. R. Chemistry in Britain, 10, 1974, pp. 118-121.

2. Allcock, H. R. Chemical Engineering News, 63, 1985, pp. 22-63.

3. Singler, R. E., Hagnauer, G. L., Schneider, N. S., Laliberte, B. R., Sacher, R. E. and Matton, R. W. Journal of Polymer Science, Polymer Chemistry Edition, v. 12, 1974, pp. 433-444.

4. Allcock, H. R., Kugel, R. L. and Valan, K. J. Inorganic Chemistry, v. 5, 1966, pp. 1709-1715.

5. Infrared Spectroscopy Committee of the Chicago Society for Coatings Technology, An Infrared Spectroscopic Atlas for the Coating Industry, Federation of Societies for Coatings Technology, Philadelphia, PA, 1980, p. 346.

6. McCaffrey, R. R., McAtee, R. E., Grey, A. E., Allen, C. A., Cummings, D. G. and Appelhans, A. D. Journal of Membrane Science, v. 28, 1986, p. 47.

7. Starzak, M. E. The Physical Chemistry of Membranes, Academic Press, New York, NY, 1984, pp. 230-237.

8. McCaffrey, R. R., McAtee, R. E., Grey, A. E., Allen, C. A., Cummings, D. G. and Appelhans, A. D. Journal of Membrane Science, v. 28, 1986, pp. 47-67.

9. Early, J. E. and Cannon, R. D. Transition Metal Chemistry, v. 1, 1965, pp. 33-107.

10. Pauling, L. Nature of the Chemical Bond, Cornell University Press, Ithaca, NY, 2nd ed., 1945. 